\title{
Anatomy of Failures: Stability Requirements in All Stages of Operations
}

\author{
Piotr Moncarz ${ }^{1 *}$ and Cliff Bishop ${ }^{2}$ \\ ${ }^{1}$ Ph.D, PE, NAE, Senior Fellow, Principal Engineer, Exponent; Adjunct Professor, Stanford University \\ ${ }^{2}$ Ph.D, PE, SE, Managing Engineer, Exponent Inc., Atlanta, Georgia, USA
}

\begin{abstract}
The paper provides examples of how temporary conditions experienced during construction, retrofit, or repair can bring an otherwise robust structure to failure. The KTVO Tower near Kirksville, Missouri, USA, guyed by seven tiers of guy cables, stood $610 \mathrm{~m}$ tall, until it suddenly collapsed on June 2, 1988. The collapse occurred during the replacement of potentially defective braces. The Tower had been subject to severe weather conditions, as well as having previously lost some braces; and yet, the experienced repair company brought it down through altered brace replacement employed by the repair crew. How did it happen? This paper goes through all the stages of this tragic event; from the failure scene back through failure analysis to the design, manufacturing, material supplies, and fatally altered repair procedure. This paper also provides an example of reinforced concrete structures which are erected with the steel reinforcement delivered to their final position as a multi-story cage lifted in-place by crane and acting as temporary independent structures. Their stability relies on proper bracing and restraint. What if some of the bracing becomes an obstacle to some activities? The paper concludes with best practices for involving a licensed professional at all stages of construction or repair in order to help prevent future collapses.
\end{abstract}

\section{The KTVO Tower Collapse}

\subsection{Introduction of the collapse}

Using cutting torches, bulldozers and a bloodhound, workers today searched in wreckage for one of three men who were replacing structural braces on a 2,000-foot $[610 \mathrm{~m}]$ television tower when it collapsed on Thursday. Bodies of the other two men, employed by Structural System Technology Inc. of McLean, Va., were found earlier. The tower, which belonged to KTVO in Kirksville, collapsed in calm weather. [excerpt from The New York Times - 4 June 1988]

\footnotetext{
* Corresponding author, moncarz@exponent.com
} 
The $581 \mathrm{~m}$ (1905 feet) tall (or $610 \mathrm{~m}$ tall including the top mast) KTVO Tower (Tower) was erected in Colony, Missouri, United States of America, in September of 1987. The tower was completed in September of 1987 with a total price tag of \$2.5 million USD (equivalent to \$5.6M USD in 2019). At the time of erection, this was one of the tallest towers in America - over twice the height of the Eiffel Tower. The Tower consisted of one central spire supported by guy wires (Fig. 1).

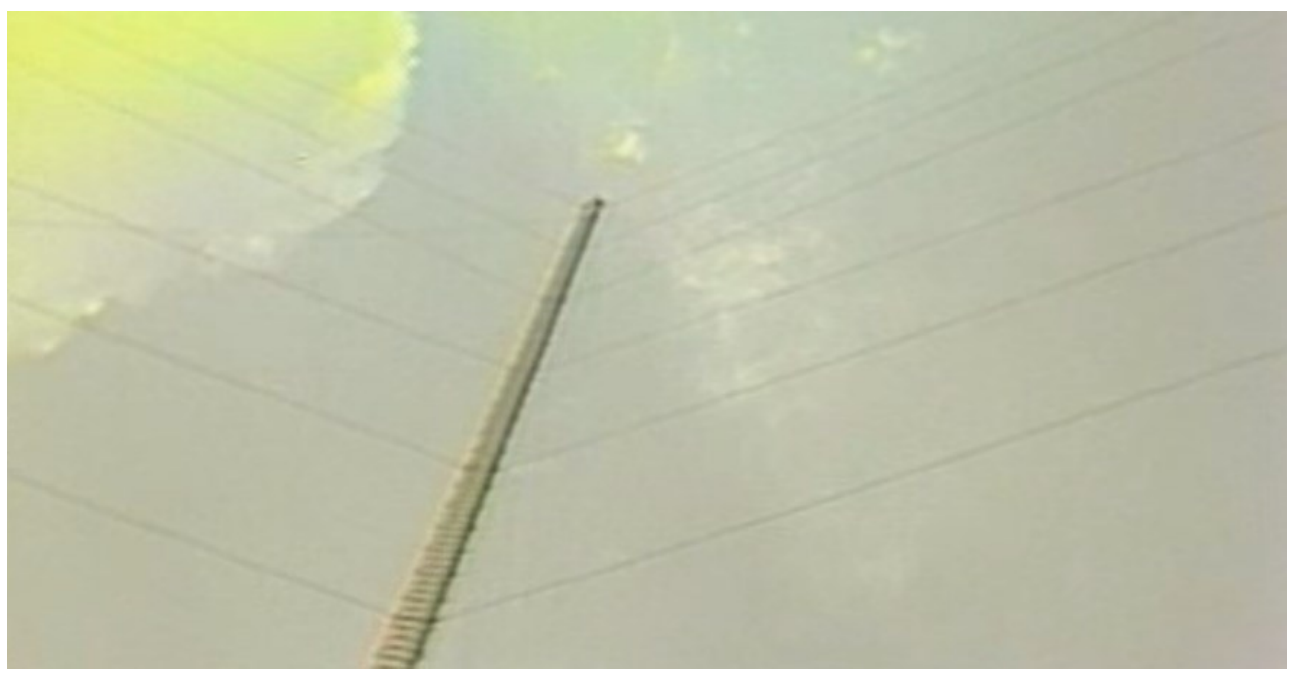

Fig. 1. KTVO-TV Tower. [Image Source: KTVO-TV (ABC)].

On June 2, 1988, brace replacement program was continued on the Tower. The replacement of diagonal braces of the Tower was dictated by numerous failures of the braces showing them to be defective. Mill certificate review, failed brace analysis, and field observed failures confirmed the need for the wholesale brace replacement. The Tower collapsed during the repair operation (Fig. 2) killing the three workers on the platform and two workers on the ground. Rescue workers and investigators were met with a tangled mass of steel, with portions of the Tower partially buried in the ground and rising over 30 feet above ground (Fig. 3). There were two items of note concerning the collapse:

1. There were no significant environmental effects (wind, rain, etc.) present at the time of collapse, and

2. The workers were performing their repairs based on a general procedure most likely to which unapproved changes were implemented. 


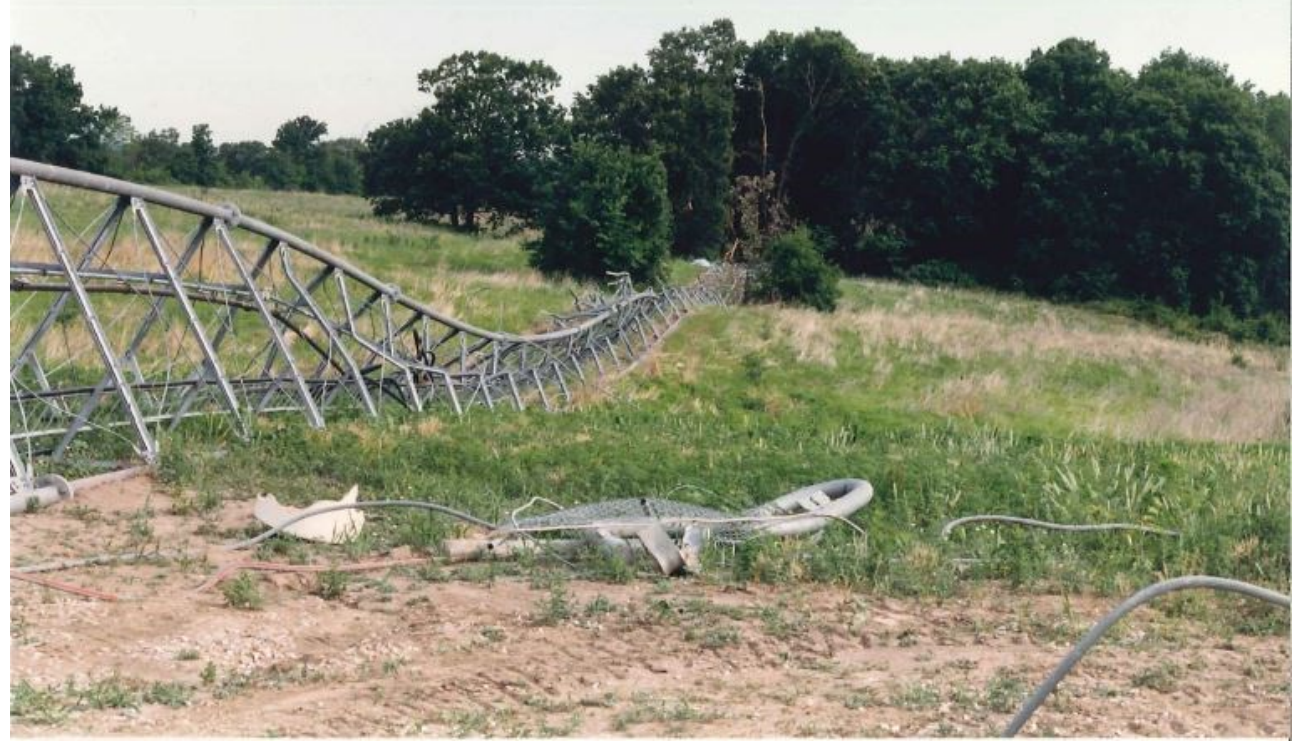

Fig. 2. Top section of collapsed Tower.

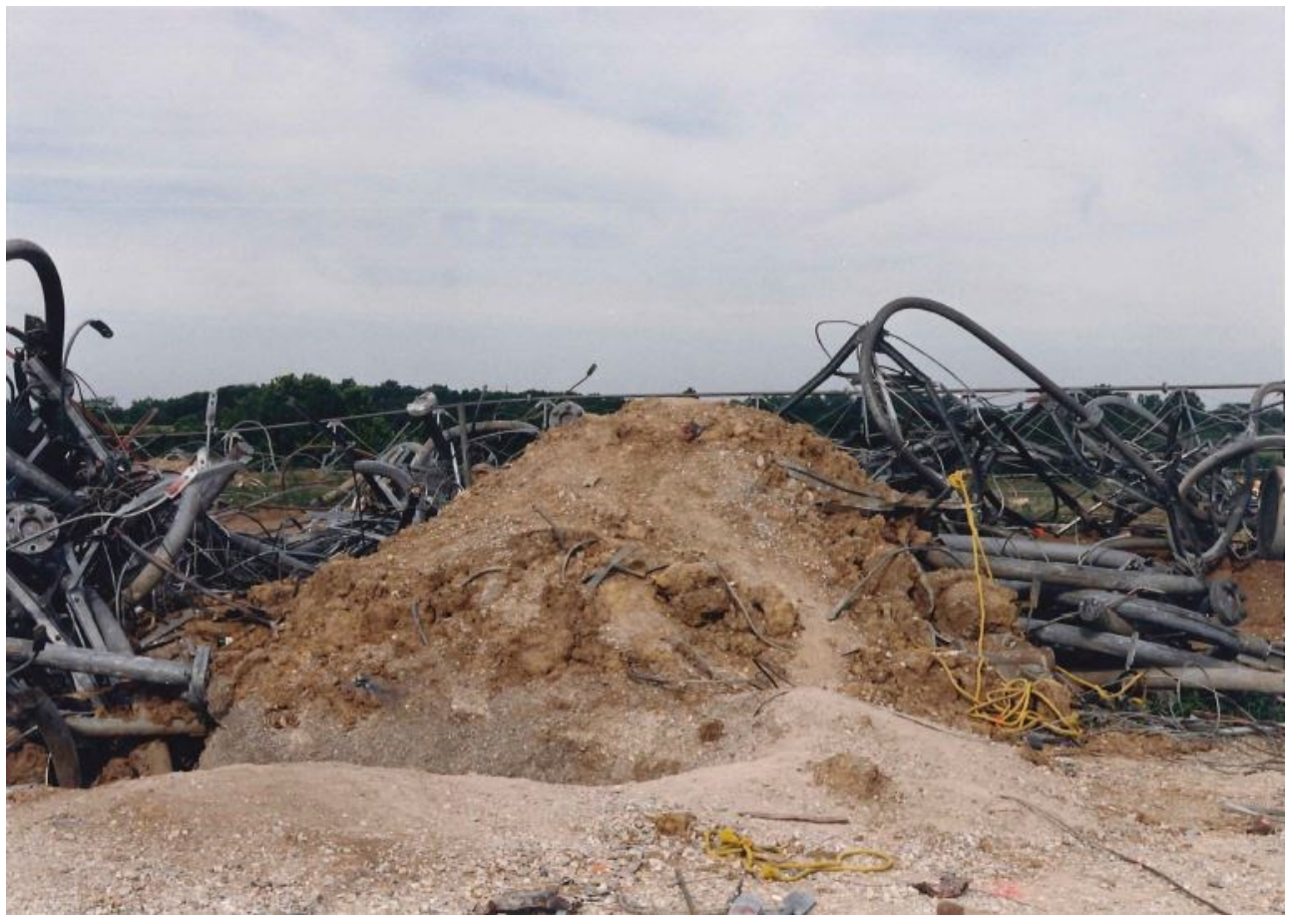

Fig. 3. Middle section of collapsed Tower. 


\subsection{The structure}

The tower was triangular shaped in plan and had diagonal $\mathrm{x}$-bracing between corner columns (Fig. 4). The steel member type by component is as follows:

- Three main columns - solid round steel ranging in diameter from $159 \mathrm{~mm}$ (6-1/4 inch) at the bottom of the structure to $102 \mathrm{~mm}$ (4 inch) at the top. The columns came in length of $9.1 \mathrm{~m}$ (30 feet) with bolted splice plates welded at the end of the column. Three tiers of diagonally braces were attached to the column segment as shown in Fig. 4;

- Horizontal truss members - steel double-angles;

- Internal diagonal bracing - round steel bars. The bar diameters were $25 \mathrm{~mm}$ (1 inch), $21 \mathrm{~mm}$ (7/8 inch), $19 \mathrm{~mm}$ (3/4 inch), and $16 \mathrm{~mm}(5 / 8 \mathrm{inch})$. At the ends of the bars, connecting plates were welded to provide a bolting connection to joint tabs welded to the legs of the tower. To avoid net compression in the diagonals they were fabricated shorter and mounted under tension (potentially up to the yield level) in their final configuration; and

- Guy wires - $29 \mathrm{~mm}$ (1 1/8 inch) to $35 \mathrm{~mm}$ (1 3/8 inch) diameter bridge cables.
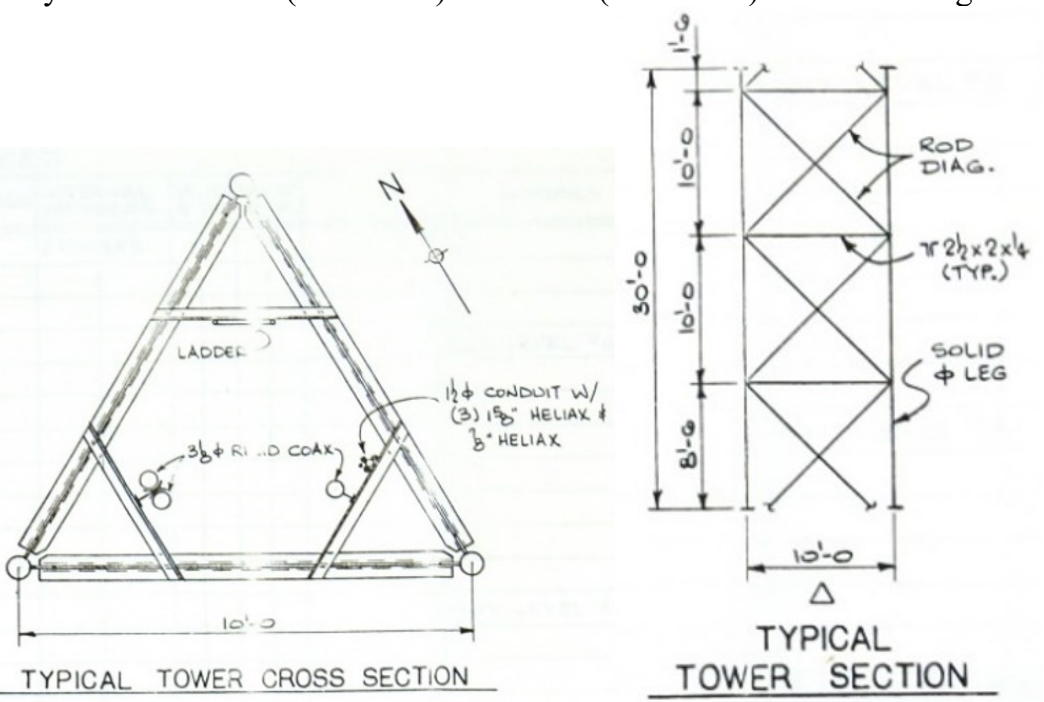

Fig. 4. Tower layout (plan at left, elevation at right).

There were a total of thirty guy wires installed over the height of the Tower; ten sets of three, radially positioned at 120 degrees from the Tower's center (Fig. 5). The guy wires were anchored to the ground at three anchor points at each azimuth: 3 lowest elevation lines were anchored at $145 \mathrm{~m}$ from the center of the base of the tower, 3 higher elevation lines were anchored at $290 \mathrm{~m}$ from the center, and the 4 top elevation lines were anchored $411 \mathrm{~m}$ from the center. 


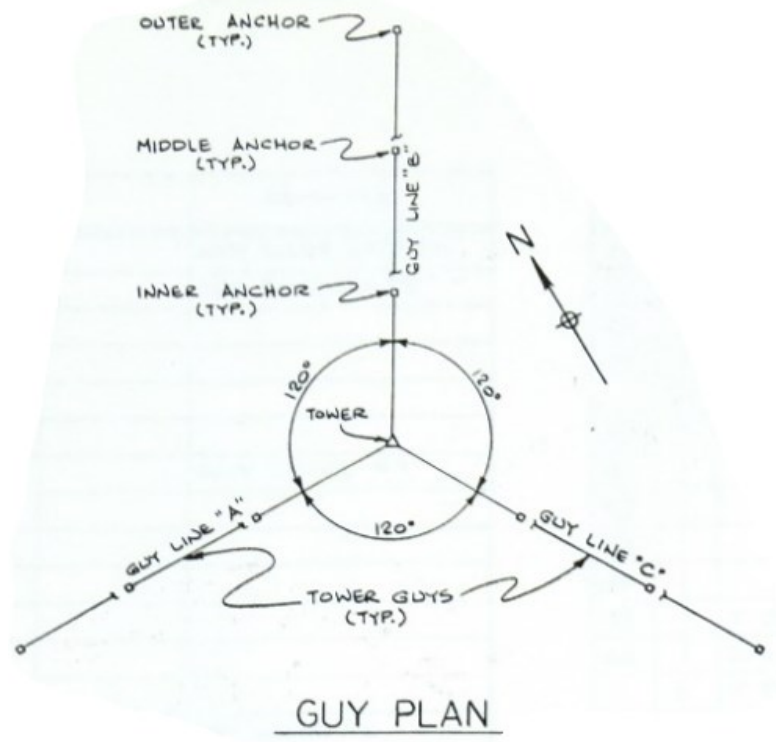

Fig. 5. Guy wire configuration in plan.

The bottom 15 feet of the Tower tapered as a pyramid to a single point (Fig. 6). The base of the tower was anchored to a $250 \mathrm{~mm}(10 \mathrm{inch})$ thick steel base plate which was then anchored with bolts into the concrete foundation.

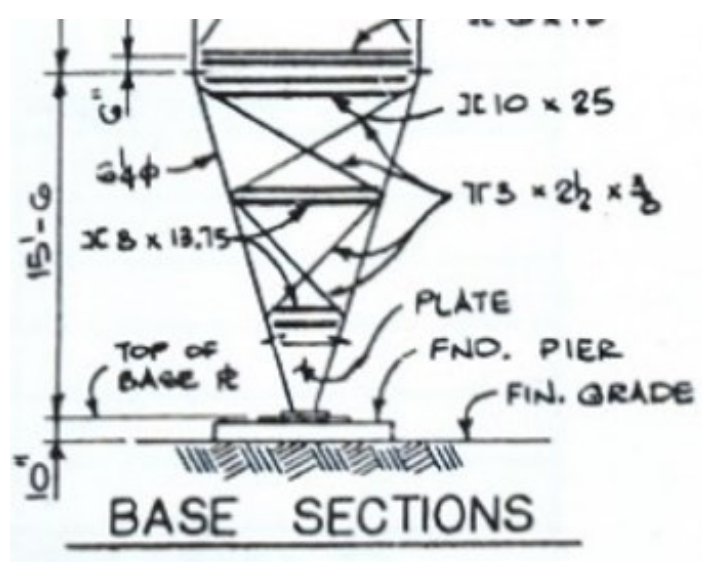

Fig. 6. Tower tapered into a single point at the bottom elevation.

\subsection{Failure analysis}

Prior to initial operation of the Tower, two diagonal rods failed at the connection tab (Fig. 7). The testing laboratory determined the failure was caused by "weld undercut and thermal shock." Within days of operation, laboratory tests showed the $16 \mathrm{~mm}$ (5/8-inch) diameter diagonal brace rods have $0.32 \%$ carbon content equivalent, thus would have required special welding. Mill certificates (Table 1.) show the steel of diagonal rods installed in the tower deviate greatly from specifications (nominal yield of $345 \mathrm{MPa}(50 \mathrm{ksi})$ ). The engineering firm/builder informed the steel supplier of the unacceptable quality of the steel rods. More rod breaks occur over the next few months at the rod-to-connector plate location. 


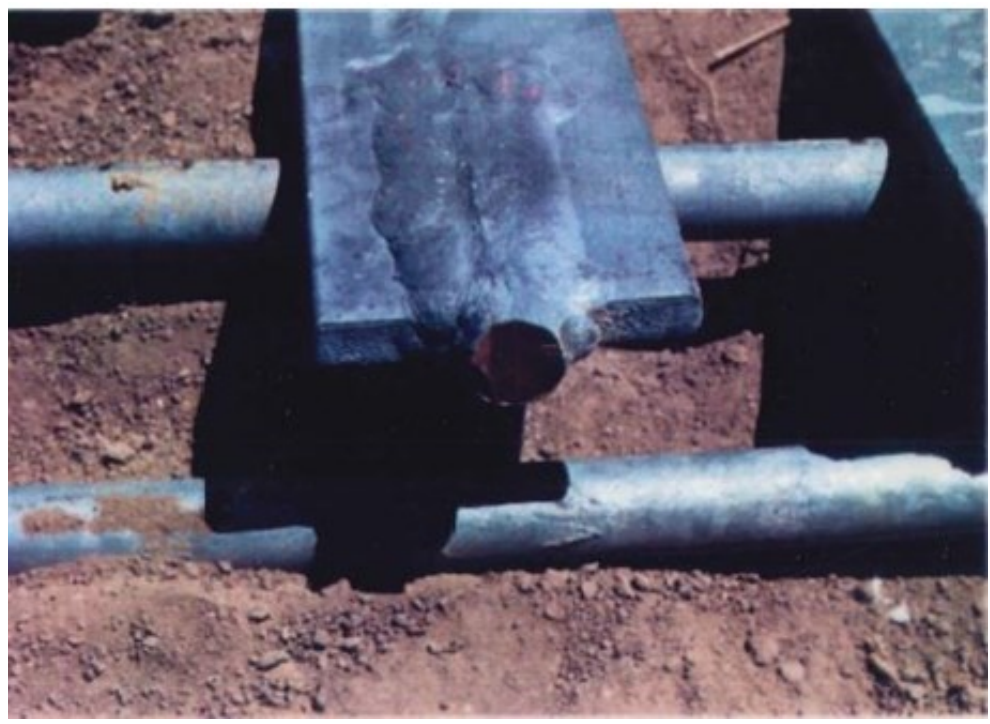

Fig. 7. Brace rod failure at the connecting tab plate.

Table 1. Mill certification result for the specified steel of nominal 50 ksi yield strength.

\section{Original Rods}

$\begin{array}{cccc}\begin{array}{c}\text { Rod } \\ \text { Diameter }\end{array} & \begin{array}{c}\text { Number } \\ \text { of Pieces }\end{array} & \begin{array}{c}\text { Yield } \\ (\mathrm{psi})\end{array} & \begin{array}{c}\text { Tensile Streng } \\ (\mathrm{psi})\end{array} \\ 5 / 8^{\prime \prime} & 626 & 72,000 & 81,500 \\ 3 / 4^{\prime \prime} & 245 & 50,000 & 55,000 \\ 7 / 8^{\prime \prime} & 289 & 45,000 & 55,500 \\ 1 " & 75 & 50,500 & 66,500\end{array}$

In view of the high frequency of the diagonal brace failures and the identified endemic fabrication defects, the design-build company decided to replace all of the diagonal brace rods (over one thousand rods total, i.e. over two thousand bolted connections). The diagonal brace replacement was carried out from a platform hoisted along the tower height. In general, the replacement was carried out starting at the top of the tower and moving downwards, tier by tier. The procedure required a 3-ton capacity come-a-long to be used to substitute for the tension force the brace provided, the brace was then removed, new brace was put in place, and the come-a-long tension was released, thus pretensioning the new brace. This procedure clearly required several moves of the platform per tier being repaired and likely seemed inefficient to the three workers on the platform and the two assistants on the ground. 
Adjustments to the procedure were made, as was apparent from a review of the records indicating an increase of the number of braces replaced per day of work as follows:

- On 5 May 1988 - 28 rods were replaced;

- On 6 May 1988 - 12 rods were replaced;

- In a following three-day period - a 114 rods were replaced (38 per day);

- In the next five-day period - $72,54,66,54$, and 60 rods per day were replaced;

- In a subsequent five-day period $-54,48,60,50$, and 54 rods per day were replaced; and

- On the last day of repair, 39 rods were replaced in the morning at which time the tower collapsed.

At the time of collapse, the three workers were replacing braces at approximately $150 \mathrm{~m}$ (500 feet) up the tower. The Tower collapsed in three distinct sections: 1 ) the lower $150 \mathrm{~m}$ section, 2) the top portion of about $150 \mathrm{~m}$, and 3) the middle portion of approximately 300 $\mathrm{m}$. The top and lower portions remained fairly straight while the middle section was a crumpled mass on the ground. Fig. 8 schematically shows the tower collapse sections. One of the straight sections is shown previously in Fig. 2. A portion of the crumpled middle section is shown in Fig. 3.



Fig. 8. Tower collapse sections.

An investigation of the accident site consisted of capturing the geometry of the downed tower and recovering key sections which might help to determine the reason for the collapse. At the time of collapse, the workers were replacing sections at about $150 \mathrm{~m}$ height; roughly corresponding to the joint between sections 17 and 18 of the tower, which is approximately where the fatal tower break occurred. This location also was slightly below the attachment of Guy Wire \#3 which occurred between sections 18 and 19. Fig. 9 schematically shows the recovered and retained tower column sections of sections 17 and 18 . 


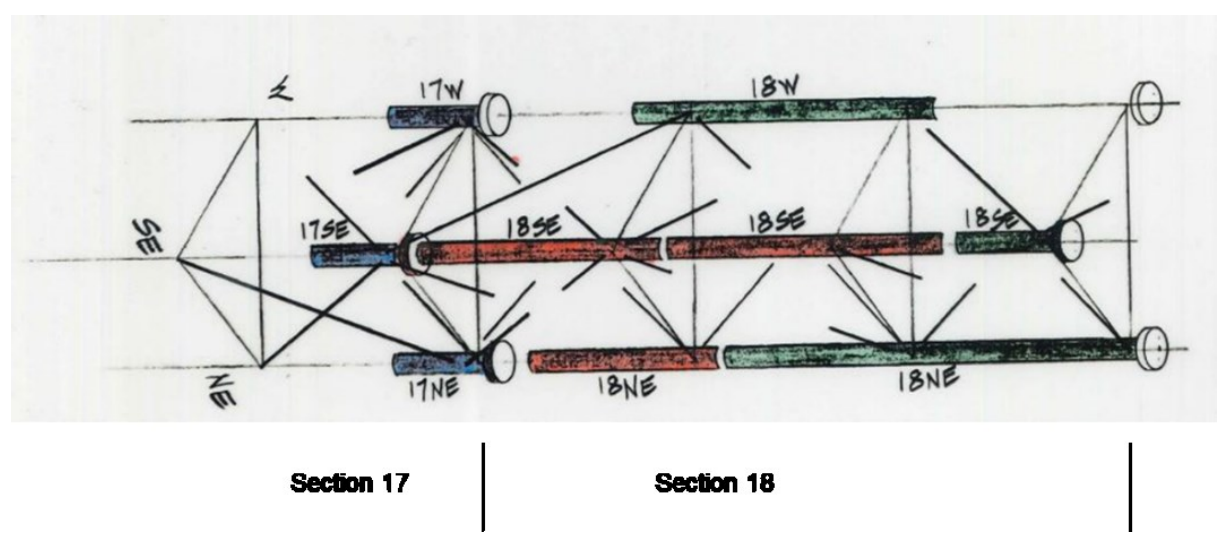

Fig. 9. Recovered tower column sections.

Structural analyses, using a three dimensional model of the cable-guyed structure, revealed the tower to be stable with all diagonals intact. Removal of individual diagonals or diagonals within the same tier on one face had no impact on the stability of the tower; however, removal of adjacent diagonals on adjacent tiers, one above and one below a column splice joint, lead to opposite direction (twisting) rotation of the tower, subjecting the splice bolts to excessive shear forces. Such diagonal removal/replacement was inconsistent with the repair procedures specified. The analysis thus supported the scenario consistent with the debris layout of the tower collapse initiation through failure of a column splice joint between sections 17 and 18 caused by excessive number of braces being removed at the same time by the repair crew.

\subsection{KTVO Tower collapse conclusions}

After significant research and analysis of the tower and taking into account the altered repair process, it was determined that the following issues contributed to the tower's collapse:

1. The brace material provided for the project was inconsistent with the design/fabrication assumptions,

2. The material specifications were not precise enough to prevent such an error,

3. Incorrect steel was supplied for the tower braces,

4. Material testing lagged not only behind the fabrication but even erection of the tower, thus providing information about the defective rod material and welding procedure inadequacies only after the tower was already completed, and

5. The repair of the tower was carried out with procedures adjusted by the repair team and without engineering input, leading to torsional instability of the tower.

A key lesson from this tragic failure is that when repair of an existing structure is carried out, the static and dynamic conditions of the structures during the individual repair stages have to be defined and analyzed. Once defined, repair procedure may not be modified without prior approval based on appropriate engineering analysis.

\section{Column Reinforcing Cages}

Another common occurrence where an engineer does not often contemplate a work plan is in the erection of column reinforcing cages. In the United States, the erection of structures is often left to the contractors' means and methods; therefore, there is rarely a comprehensive plan to address stability concerns before the structure is completed. For the case of concrete construction, the reinforcing cage is often tied together on the ground, lifted into place using 
a crane or hoist, and then secured in place using temporary bracing (Fig. 10). The location, quantity, and type of bracing installed is often based on the wisdom and experience of the iron worker.

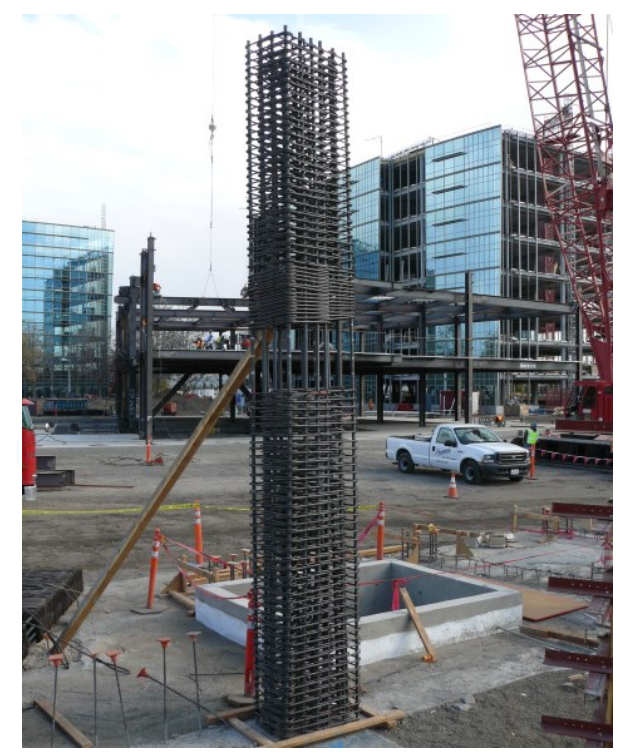

Fig. 10. Reinforcing cage with temporary bracing.

Bishop and Uriz [6] and Bishop, Uriz, and McDonald [7] studied in-depth the issues that one must consider in order to correctly utilize temporary bracing on concrete reinforcing cages. Their research was, in part, driven by a collapse of a rebar cage during construction. In the instance in question, the worker did not have a plan as how to install the formwork around the rebar cage while the temporary bracing was in the way. While hanging from the top of a nearly two-story rebar cage, the worker disconnected a brace in order to construct the formwork. Once the brace was disconnected and given the eccentric loading caused by the worker hanging from the cage, the cage collapsed upon the worker, causing serious injury. An example of a dramatic concrete reinforcement cage collapse is shown in Fig. 11.

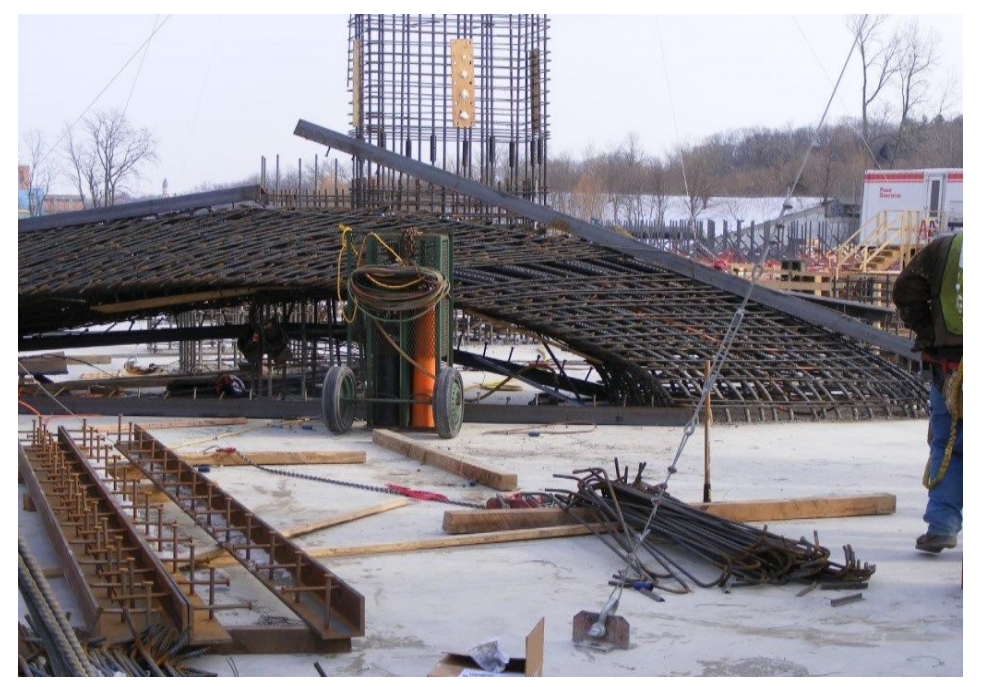

Fig. 11. Collapsed reinforcing cage. 


\section{Engineering Requirements}

Structures in the United States are most often constructed in compliance with building codes deemed applicable by the local building official. These codes reference and incorporate tradespecific standards such as the American Concrete Institute's (ACI) standard 318 (Building Code Requirements for Structural Concrete and Commentary) or the American Institute of Steel Construction's (AISC) standard 360 (Specification for Structural Steel Buildings). Each code and standard has specific requirements for what type of documentation or work plans should be produced for any new construction or repair of existing construction.

For example, the 2012 International Building Code (IBC) requires in Section 107 that "submittal documents consisting of construction documents, statement of special inspections, geotechnical report and other data shall be submitted in two or more sets with each permit application [8]." This means that for any permit that is pulled for new construction or a repair, construction documents should be produced for review by the building official. Section 107 goes on to require that the "construction documents shall be prepared by a registered design professional where required by the statues of the jurisdiction in which the project is to be constructed." That is, an engineer, who is often the registered design professional charged with building safety, would need to produce a set of construction documents, affix their seal, and have the documents reviewed by a local building official before construction can commence.

Contrary to the IBC, the AISC Specification in effect at the time of the tower's construction does not provide explicit requirements for documentation to be produced [5]; however, the 1986 AISC Code of Standard Practice discusses where the responsibilities lie for shop and erection drawings [4]. In essence, it is the owner's (which includes the owner's representatives such as the architect and engineer-of-record) responsibility to provide "complete structural steel plans and specifications released for construction" so the fabricator can prepare "[complete] shop and erection drawings."

\section{Conclusions and Recommendations}

Based on the two failures discussed herein, the lack of a properly contemplated and executed, engineer-approved work plan ultimately led to the collapses. Had there been an enforced plan in place, workers would have been able to safely perform their trades while avoiding undue risks to which they may not have been aware. The following steps are recommended as best practices to avoid future incidents:

1. Determine the work to be completed,

2. Assess the impact of that work on the static and dynamic stability of the structure at each stage of the procedure,

3. Create a comprehensive work plan including such things as sequencing and staging that is reviewed for safety by a properly licensed design professional, and

4. Commence work, while reserving the right to pause operations if, for instance, additional components must be adjusted in order to make the planned changes.

Following this type of procedure does not guarantee that no problems will occur; it is simply one option that interjects a registered design professional into the process. These professionals, by order of statues, are charged with protecting life-safety. When one considers what is at stake given an error, the inconvenience to the budget and schedule by having a design professional review the process is relatively minor. 


\section{References}

1. P.D. Moncarz, P.S. Noakowski, Damage by Hurricane Andrew to Reinforced Concrete Stacks in Florida (Proceedings of the $45^{\text {th }}$ Meeting of the International Committee on Industrial Chimneys, CICIND, Orlando, Florida, 1996)

2. P.D. Moncarz, R.K. Taylor, J. Perform. Constr. Fac. 14(2) (2000)

3. P.D. Moncarz, B.J. Lahnert, R.F. Hooley, J.D. Osteraas, J. Perform. Constr. Fac. 6(4), pp. 232-245 (1992)

4. AISC COSP. Code of Standard Practice for Steel Buildings and Bridges (American Institute of Steel Construction, 1986)

5. AISC LRFD. Load and Resistance Factor Design Specification for Structural Steel Buildings (American Institute of Steel Construction, 1986)

6. C.D. Bishop, P. Uriz, Column Reinforcing Cage Stability and Construction Safety (Proceedings of the Forensic Engineering $7^{\text {th }}$ Congress: Performance of the Built Environment. Miami, FL, USA, 2015)

7. C.D. Bishop, P. Uriz, B. McDonald, Stability of Column Rebar Cages for Building under Construction (Proceedings of the Annual Stability Conference. Structural Stability Research Council. Nashville, TN, USA, 2015)

8. International Building Code (International Code Council, 2012) 